\title{
SAXS study of ion tracks in San Carlos olivine and Durango apatite
}

\author{
B. Afra ${ }^{\text {a,* }}$, M.D. Rodriguez ${ }^{\text {a }}$, M. Lang ${ }^{\text {b }}$, R.C. Ewing ${ }^{\text {b }}$, N. Kirby ${ }^{c}$, C. Trautmann ${ }^{\text {d }}$, P. Kluth ${ }^{\text {a }}$ \\ ${ }^{a}$ Department of Electronic Materials Engineering, Research School of Physics and Engineering, The Australian National University, Canberra, ACT 0200, Australia \\ ${ }^{\mathrm{b}}$ Department of Geological Sciences, University of Michigan, Ann Arbor, MI 48109-1005, USA

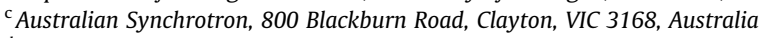 \\ ${ }^{\mathrm{d}}$ GSI Helmholtz Centre for Heavy Ion Research, Planckstrasse 1, Darmstadt D-64291, Germany
}

\section{A R T I C L E I N F O}

\section{Article history:}

Received 12 August 2011

Received in revised form 1 March 2012

Available online $\mathrm{xxxx}$

\section{Keywords:}

Ion tracks

SAXS

Minerals

Olivine

Apatite

Ion track annealing

\begin{abstract}
A B S T R A C T
Ion tracks were generated in crystalline San Carlos olivine $(\mathrm{Mg}, \mathrm{Fe})_{2} \mathrm{SiO}_{4}$ and Durango apatite $\mathrm{Ca}_{10}\left(\mathrm{PO}_{4}\right)_{6} \mathrm{~F}_{2}$ using different heavy ions $\left({ }^{58} \mathrm{Ni},{ }^{101} \mathrm{Ru},{ }^{129} \mathrm{Xe},{ }^{197} \mathrm{Au}\right.$, and $\left.{ }^{238} \mathrm{U}\right)$ with energies ranging between $185 \mathrm{MeV}$ and $2.6 \mathrm{GeV}$. The tracks and their annealing behavior were studied by means of synchrotron based small angle X-ray scattering in combination with in situ annealing. Track radii vary as a function of electronic energy loss but are very similar in both minerals. Furthermore, the annealing behavior of the track radii has been investigated and preliminary results reveal a lower recovery rate of the damaged area in olivine compared with apatite.
\end{abstract}

(c) 2012 Elsevier B.V. All rights reserved.

\section{Introduction}

Ion tracks are long narrow defect structures that are generated by the high electronic excitations that swift heavy ions cause as they traverse through a solid. Ion tracks in minerals and their behavior upon thermal annealing provide the critical basis for geochronology/thermochronology, archeology, and astrophysics. In natural apatite and olivine, ion tracks have been extensively investigated for their applications in fission track dating and for identification of cosmic rays in meteorites, respectively [1,2]. At elevated temperatures, ion tracks shrink in size and fragment into sections until they are completely annealed. Thus, the length and morphology of fission tracks can be used to determine the thermal history of Earth's crust and meteorites [3-5].

Different techniques have been employed to study ion tracks and their properties in minerals, including chemical etching [6], transmission electron microscopy (TEM) [7-9], and Rutherford backscattering spectroscopy [10]. In addition, different groups have studied the annealing properties of tracks in apatite [11-14] and olivine $[4,15]$. These experiments predominantly utilize chemical etching and investigate empirically the effect of annealing on the number density and length distribution of the etched tracks [11-13]. Etching, however, erases the primary damage structure of the track, thus, essential information on the actual scale of the underlying radiation damage is irrevocably lost. Small angle X-

\footnotetext{
* Corresponding author. Tel.: +61 261251593.

E-mail address: baf109@physics.anu.edu.au (B. Afra).
}

ray scattering (SAXS) can be used as an alternative technique to study ion track damage as it measures density changes at the nanometer scale [16]. Recent SAXS measurements provided details of the track structure in amorphous $\mathrm{SiO}_{2}[17,18]$ and natural apatite [19]. Using in situ and ex situ annealing experiments, it was demonstrated that SAXS is well suited for monitoring the annealing kinetics of ion tracks.

In this work we have applied SAXS to measure track radii in olivine and Durango apatite, the latter of which complement earlier results [19]. Moreover, we show preliminary results on isothermal annealing of ion tracks in olivine and compare them to previous results on apatite [19].

\section{Experiment}

Crystalline samples of Durango apatite and San Carlos olivine (95\% $\mathrm{Mg}_{2} \mathrm{SiO}_{4}$ ) with thicknesses of $30-50 \mu \mathrm{m}$ were irradiated with swift heavy ions. The irradiation experiments were performed using ${ }^{58} \mathrm{Ni},{ }^{101} \mathrm{Ru},{ }^{129} \mathrm{Xe},{ }^{197} \mathrm{Au}$, and ${ }^{238} \mathrm{U}$ ions with energies between 0.6 and $2.6 \mathrm{GeV}$ at the UNILAC accelerator at GSI in Germany. At the ANU Heavy Ion Accelerator Facility, apatite samples were irradiated with $185 \mathrm{MeV}{ }^{197} \mathrm{Au}$ ions. Irradiation was performed at room temperature under normal incidence. Details of the irradiation parameters are given in Table 1, where the values for the surface electronic energy loss $\mathrm{dE} / \mathrm{dx}$, and the ion range were calculated using SRIM 2008 [20]. Irradiation fluences ranged from $5 \times 10^{10}$ (well separated ion tracks) to $2 \times 10^{12}$ ions $/ \mathrm{cm}^{2}$ (overlapping tracks). 
Table 1

Irradiation parameters and track radii extracted from SAXS measurements.

\begin{tabular}{|c|c|c|c|c|c|c|c|c|c|}
\hline Sample & $\begin{array}{l}\text { Sample thickness } \\
(\mu \mathrm{m})\end{array}$ & $\begin{array}{l}\text { Fluence (ions/ } \\
\mathrm{cm}^{2} \text { ) }\end{array}$ & Ion & $\begin{array}{l}\text { Ion energy } \\
(\mathrm{MeV})\end{array}$ & $\begin{array}{l}\text { Electronic energy loss } \\
(\mathrm{keV} / \mathrm{nm})\end{array}$ & $\begin{array}{l}\text { Projected range } \\
(\mu \mathrm{m})\end{array}$ & $\begin{array}{l}\text { Radius } \\
(\mathrm{nm})\end{array}$ & $\begin{array}{l}\text { Radius } \\
\text { polydispersity (nm) }\end{array}$ & Reference \\
\hline Olivine & 40 & $2 \times 10^{11}$ & ${ }^{58} \mathrm{Ni}$ & 644 & 6 & 88 & $1.8 \pm 0.2$ & $0.5 \pm 0.2$ & $\begin{array}{l}\text { Present } \\
\text { work }\end{array}$ \\
\hline Olivine & 40 & $5 \times 10^{10}$ & ${ }^{101} \mathrm{Ru}$ & 1121 & 13 & 81 & $2.7 \pm 0.1$ & $0.4 \pm 0.1$ & $\begin{array}{l}\text { Present } \\
\text { work }\end{array}$ \\
\hline Olivine & 40 & $5 \times 10^{10}$ & ${ }^{197} \mathrm{Au}$ & 2187 & 26.2 & 90 & $4.6 \pm 0.1$ & $0.3 \pm 0.1$ & $\begin{array}{l}\text { Present } \\
\text { work }\end{array}$ \\
\hline Olivine & 40 & $5 \times 10^{10}$ & ${ }^{238} \mathrm{U}$ & 2642 & 34.4 & 87 & $5.3 \pm 0.1$ & $0.4 \pm 0.1$ & $\begin{array}{l}\text { Present } \\
\text { work }\end{array}$ \\
\hline Apatite & 50 & $5 \times 10^{10}$ & ${ }^{238} \mathrm{U}$ & 2047 & 37.5 & 66 & $5.5 \pm 0.1$ & $0.3 \pm 0.1$ & $\begin{array}{l}\text { Present } \\
\text { work }\end{array}$ \\
\hline Apatite & $40-50$ & $\begin{array}{l}5 \times 10^{10} \\
1 \times 10^{12}\end{array}$ & ${ }^{197} \mathrm{Au}$ & 185 & 23.4 & 15 & $5.5 \pm 0.1$ & $0.5 \pm 0.2$ & $\begin{array}{l}\text { Present } \\
\text { work }\end{array}$ \\
\hline Apatite & 30 & $2 \times 10^{12}$ & ${ }^{58} \mathrm{Ni}$ & 644 & 6.3 & 83 & $1.8 \pm 0.1$ & $0.3 \pm 0.1$ & [19] \\
\hline Apatite & 30 & $5 \times 10^{10}$ & ${ }^{101} \mathrm{Ru}$ & 1121 & 13.5 & 76 & $2.9 \pm 0.1$ & $0.2 \pm 0.1$ & [19] \\
\hline Apatite & 40 & $5 \times 10^{10}$ & ${ }^{129} \mathrm{Xe}$ & 1432 & 18.6 & 75 & $3.6 \pm 0.1$ & $0.3 \pm 0.1$ & [19] \\
\hline Apatite & 30 & $5 \times 10^{10}$ & ${ }^{197} \mathrm{Au}$ & 2187 & 27.3 & 85 & $4.8 \pm 0.1$ & $0.2 \pm 0.1$ & [19] \\
\hline
\end{tabular}

Transmission SAXS measurements were performed at the SAXS/ WAXS beamline at the Australian Synchrotron with an X-ray energy of $12 \mathrm{keV}$ and a camera length of approximately $1600 \mathrm{~mm}$. Mounting the samples on a three-axis goniometer allowed for precise alignment of the ion tracks with respect to the X-ray beam. Measurements were taken with the ion tracks tilted by $0^{\circ}, 5^{\circ}$ and $10^{\circ}$ with respect to the X-ray beam and spectra were collected with a Pilatus $1 \mathrm{M}$ detector with exposure times of 5 and $10 \mathrm{~s}$. Scattering from un-irradiated samples was measured for background removal and the absolute scattering was calibrated using a glassy carbon standard [21].

In order to study the ion track recovery, isothermal annealing was carried out in situ on the olivine and apatite samples irradiated with $2.2 \mathrm{GeV}$ Au ions. A hot-air heater was positioned underneath the sample, and the temperature was monitored using a thermocouple at sample height. The samples were kept at $350^{\circ} \mathrm{C}$ for about $6 \mathrm{~h}$, and SAXS measurements were taken approximately every $40 \mathrm{~s}$. A more detailed description of track annealing in apatite is reported in Ref. [19].

\section{Results and discussion}

Fig. 1(a) and (c) show isotropic scattering images from the ion tracks in olivine and apatite, respectively, when the ion track axis is nearly parallel to the X-ray beam. Tilting the sample by $10^{\circ}$, for example, results in highly anisotropic scattering in the form of narrow streaks that are shown in Fig. 1(b) and (d). This anisotropy results from the high aspect ratio of the ion tracks, which are only a few nanometers wide and up to tens of micrometers long. X-ray intensities of radial sectors perpendicular to the streaks in the anisotropic images resemble those of unirradiated samples. This suggests the lack of significant density fluctuations on the nanometer length scale along the ion tracks.

Scattering intensities extracted from the streaks for olivine samples irradiated with different ion/energy combinations are plotted in Fig. 2. From the strong oscillations, largely monodisperse radii and sharp transitions between the track densities and the surrounding matrix material can be inferred. The best model that adequately fits the observed scattering for all irradiation conditions is a simple cylinder model with a constant density, different from that of the matrix material. The form factor of this model can be written as:

$f(q)=2 \pi L R \rho_{0} \frac{J_{1}(R q)}{q}$

where $q$ is the scattering vector, $L$ the length of the track, $R$ the track radius, $\rho_{0}$ the density difference between track and matrix, and $J_{1}$ is the first order Bessel function. A narrow Gaussian distribution of
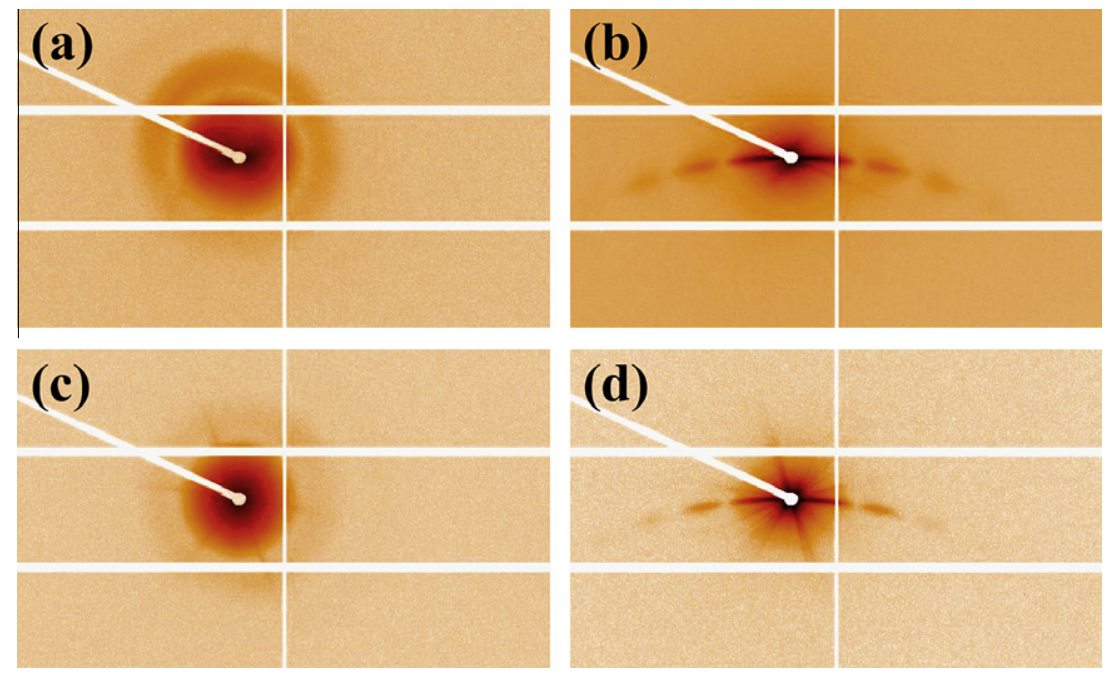

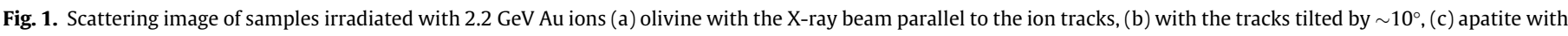
the X-ray beam parallel to the ion tracks, (d) with the tracks tilted by $\sim 10^{\circ}$. 


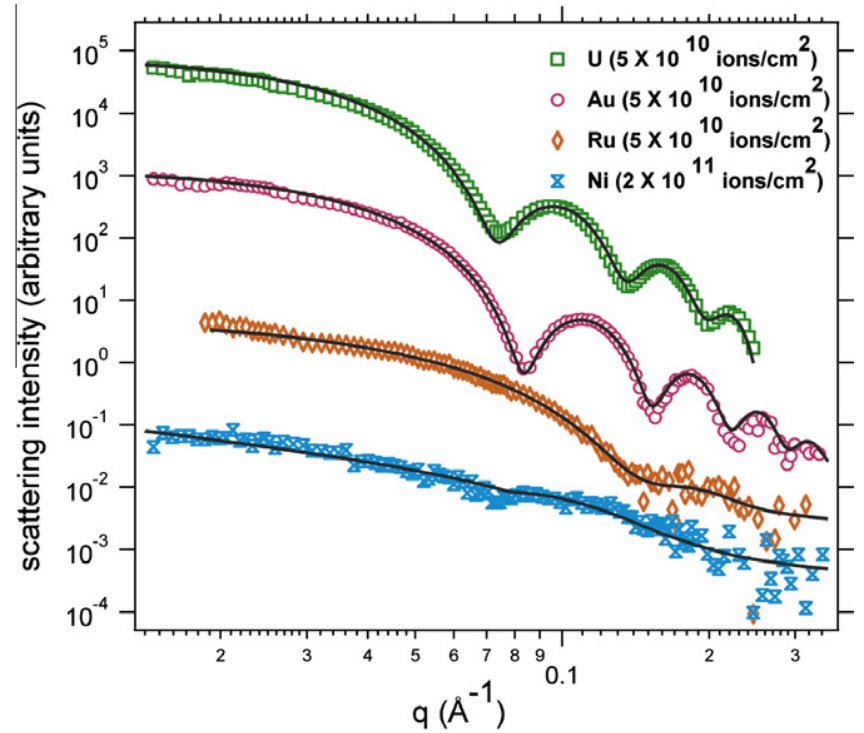

Fig. 2. SAXS scattering intensity from ion tracks in olivine (symbols) and corresponding fits with the hard cylinder model (solid lines) for different irradiation conditions (see Table 1).

track radii was implemented to account for deviations of perfectly aligned cylindrical tracks. This model has been previously used to fit the scattering intensity from ion tracks in Durango apatite [19]. The solid lines in Fig. 2 show the analytical fits to this model.

Fig. 3 presents the scattering spectra from ion tracks in apatite irradiated with $185 \mathrm{MeV}$ Au ions after background removal for different irradiation fluences along with their corresponding fits to the hard cylinder model. The scattering intensities are normalized to the length of the track and approximately scale with the ion fluence or equivalently the number of tracks generated in the samples. This is an indication that ion track overlap effects are negligible. We can estimate the amount of track overlap using an overlap model: $d=1-\exp \left(-\pi R^{2} \phi\right)$ [22], where $d$ is the area of the modified material, $R$ is the track radius and $\phi$ is the ion fluence. With a fluence of $5 \times 10^{10}$ ions $/ \mathrm{cm}^{2}$, which is mostly used for our irradiation experiments, the amount of track overlap is less than $1 \%$ for all track radii extracted from the SAXS measurements indicating largely isolated tracks. In apatite irradiated with $185 \mathrm{MeV}$, a track radius of $\sim 5.5 \mathrm{~nm}$ yields $\sim 20 \%$ track overlap at a fluence of $1 \times 10^{12}$ ions $/ \mathrm{cm}^{2}$ which becomes apparent as an attenuation of the oscillations in the scattering spectra (see Fig. 3).

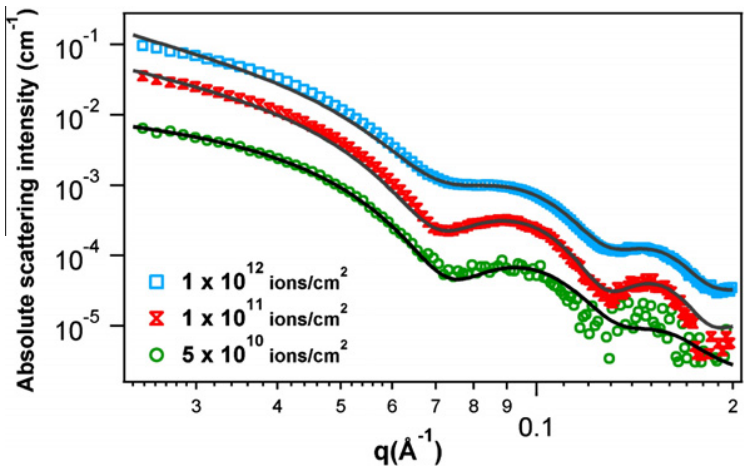

Fig. 3. Absolute scattering intensities from ion tracks in apatite samples irradiated with $185 \mathrm{MeV}$ Au ions after background removal as a function of scattering vector $q$. The solid lines are the corresponding fits to the hard cylinder model.
The applicability of the model assuming a constant density in the ion tracks with sharp boundaries to the matrix material is consistent with the formation of amorphous tracks in both materials $[23,24]$. The track radii are plotted as a function of the electronic energy loss $\mathrm{dE} / \mathrm{dx}$ in Fig. 4 . The polydispersity of the track radius or equivalently the width of the Gaussian distribution amounts to $10 \%$ of the radius or less for most irradiation conditions. The values for $d E / d x$ were calculated using SRIM2008 [20] and represent the surface energy loss of the ion. The results are also listed in Table 1. It is apparent that the ion track radii in olivine and apatite are very similar. They increase almost linearly with increasing energy loss to approximately $26 \mathrm{keV} / \mathrm{nm}$ whereafter the trend is flattened out. The plot in Fig. 4 indicates that track formation threshold in olivine is below $5 \mathrm{keV} / \mathrm{nm}$; similar to the threshold previously reported for apatite [25]. As the tracks are generated closer to the track formation threshold, the weaker oscillations in the SAXS spectra apparent in Fig. 2 can possibly result from a less homogeneous energy dissipation along the ion trajectory and resulting fluctuations in the track radial density. Low energy irradiation of both materials has also shown similar amorphization behavior under same irradiation conditions $[9,26]$.

The track radius in apatite from irradiation with $185 \mathrm{MeV} \mathrm{Au}$ is approximately $1 \mathrm{~nm}$ larger than that expected from interpolation of the higher energy irradiation experiments. This effect reflects the so called 'velocity effect' [27]. The inset in Fig. 4 shows the energy loss of Au ions in apatite as a function of the ion energy calculated by SRIM2008 [20]. $185 \mathrm{MeV}$ and $2.2 \mathrm{GeV}$ Au ions yield a similar energy loss on either sides of the so called 'Bragg peak', the maximum of electronic energy loss, but the value is reached at a different projectile velocity. For higher velocities, the projectile-induced electron cascade has a larger extension and thus lower energy density. Tracks produced at lower ion velocities have been shown to have larger radii. The larger track radius for $185 \mathrm{MeV}$ Au ions is in agreement with the velocity effect. It also should be noted that the velocity of $185 \mathrm{MeV} \mathrm{Au}$ ions is closer to the typical velocity of fission fragments that cause track formation used for geo- and thermo-chronology.

Absolute calibration of the scattering intensities enables an estimation of the density change within the ion tracks in olivine to be about $1 \pm 0.7 \%$ as compared with the crystalline matrix. This value is similar to the density change observed in apatite [19].

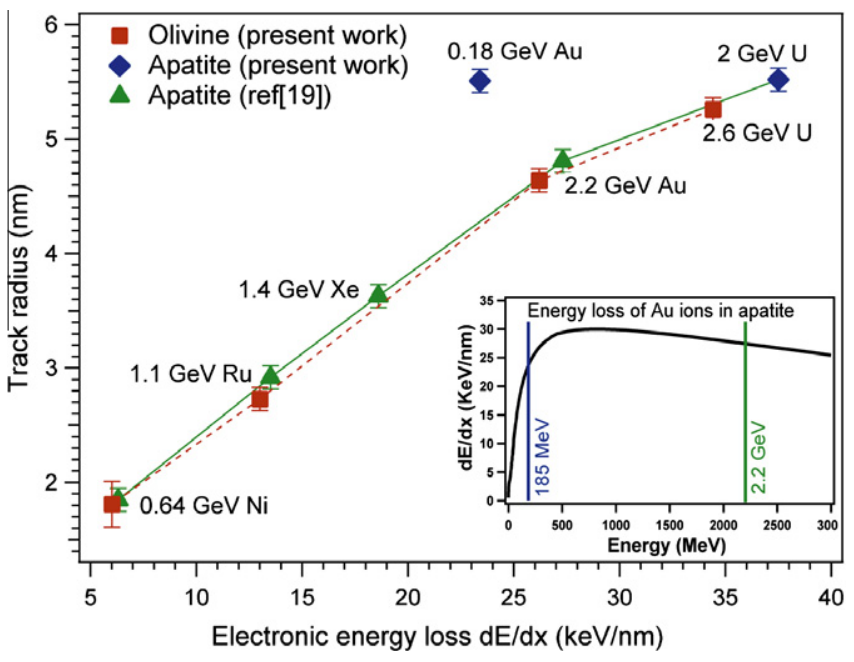

Fig. 4. Track radii as a function of electronic energy loss for different irradiation conditions; the solid and dashed lines are to guide the eye. The inset shows the electronic energy loss of Au ions as a function of energy in apatite calculated with SRIM2008. The vertical lines indicate the energy of the two different Au beams used. 


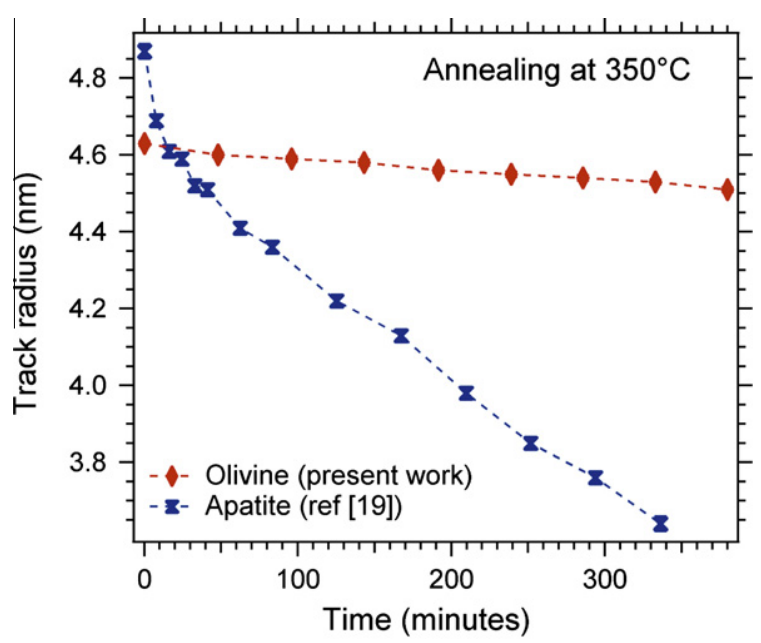

Fig. 5. Track radius as a function of annealing time for isothermal in situ annealing at $350{ }^{\circ} \mathrm{C}$ extracted from the fits for olivine and apatite. Error bars are included in the graph that in some cases are smaller than size of the data point. Dashed lines are to guide the eye.

Fig. 5 shows the track radii obtained from the in situ annealing experiments. Unlike apatite, ion tracks in the olivine sample do not show substantial change after annealing for approximately $6 \mathrm{~h}$ at $350{ }^{\circ} \mathrm{C}$. The total reduction of the track radius is less than $3 \%$ of the initial value for the olivine sample with a rate of $\sim 0.02 \mathrm{~nm} /$ hour. In contrast, identical annealing results in about $25 \%$ reduction of the track radius in apatite with a rate of $\sim 0.2 \mathrm{~nm} /$ hour, which is about a factor of 10 higher compared to olivine. The difference in the track radius reduction rate clearly indicates different recrystallization behavior despite the similar track morphology and radius prior to annealing. However, to obtain the activation energy for track annealing in olivine, further isothermal annealing experiments need to be carried out at different temperatures. At this early stage of the investigation, no definitive conclusion as to the mechanisms responsible for the different ion track annealing rates in olivine and apatite is attempted.

\section{Conclusion}

In summary, we have measured the radius of tracks created by swift heavy ions in olivine and apatite for a variety of irradiation conditions using synchrotron based SAXS. Results are consistent with the formation of amorphous ion tracks in both minerals. We have found that track radii are very similar; however, in situ annealing experiments revealed a significantly higher recrystalli- zation rate of the damaged areas in apatite as compared with olivine. Different ion velocities with similar energy loss yielded significantly different track radii in apatite consistent with the velocity effect. In order to fully address the difference of ion tracks in the two materials, further annealing experiments will be completed.

\section{Acknowledgements}

This research was undertaken at the SAXS/WAXS beamline of the Australian Synchrotron, Victoria, Australia. P.K acknowledges the Australian Research Council for financial support. Investigators at the University of Michigan were supported by the Office of Basic Energy Sciences (Grant No. DE-FG02-97ER45656).

\section{References}

[1] K. Gallagher, R. Brown, C. Johnson, Annu. Rev. Earth Planet. Sci. 26 (1998) 519.

[2] L.L. Kashkarov, N.G. Polukhina, N.I. Starkov, G.V. Kalinina, A. Ivliev, A.B. Aleksandrov, L.A. Goncharova, I.Y. Tarasova, Radiat. Meas. 43 (2008) S266.

[3] A.J.W. Gleadow, D.X. Belton, B.P. Kohn, R.W. Brown, Phosphates: Geochemical, Geobiological, and Materials Importance, vol. 48, 2002, pp. 579.

[4] J.S. Yadav, V.P. Perelygin, S.G. Stetsenko, Nucl. Tracks Radiat. Meas. 11 (1986) 55.

[5] K. James, S.A. Durrani, Earth Planet. Sci. Lett. 87 (1988) 229.

[6] S. Krishnas, D. Lal, N. Prabhu, A.S. Tamhane, Science 174 (1971) 287.

[7] T.A. Paul, P.G. Fitzgerald, Am. Mineral. 77 (1992) 336.

[8] W.X. Li, L.M. Wang, M.I. Lang, C. Trautmann, R.C. Ewing, Earth Planet. Sci. Lett. 302 (2011) 227.

[9] L.M. Wang, M.L. Miller, R.C. Ewing, Ultramicroscopy 51 (1993) 339.

[10] F. Villa et al., Radiat. Meas. 31 (1999) 65.

[11] P.F. Green, I.R. Duddy, A.J.W. Gleadow, P.R. Tingate, G.M. Laslett, Chem. Geol. 59 (1986) 237.

[12] W.D. Carlson, Am. Mineral. 75 (1990) 1120.

[13] A.S. Sandhu, S. Singh, H.S. Virk, Mineral. J. 13 (1987) 307.

[14] C. Perron, M. Maury, Nucl. Tracks Radiat. Meas. 11 (1986) 73.

[15] K.D. Crowley, M. Cameron, R.L. Schaefer, Geochim. Cosmochim. Acta 55 (1991) 1449.

[16] D. Albrecht, P. Armbruster, R. Spohr, M. Roth, K. Schaupert, H. Stuhrmann Appl. Phys. A 37 (1985) 37.

[17] P. Kluth et al., Phys. Rev. Lett. 101 (2008) 175503.

[18] P. Kluth, C.S. Schnohr, D.J. Sprouster, A.P. Byrne, D.J. Cookson, M.C. Ridgway, Nucl, Instrum. Methods Phys. Res. Sect. B 266 (2008) 2994

[19] B. Afra et al., Phys. Rev. B 83 (2011) 64116.

[20] http://www.srim.org/

[21] F. Zhang, J. Ilavsky, G.G. Long, J.P.G. Quintana, A.J. Allen, P.R. Jemian, Metall Mater. Trans. A 41A (2010) 1151.

[22] C. Riedel, R. Spohr, Radiat. Eff. 42 (1979) 69-75.

[23] S. Miro, D. Grebille, D. Chateigner, D. Pelloquin, J.P. Stoquert, J.J. Grob, J.M Costantini, F. Studer, Nucl. Instrum. Methods Phys. Res. Sect. B 227 (2005) 306

[24] T. Tagami and P.B. O'Sullivan, Low-Temperature Thermochronology: Techniques, Interpretations, and Applications vol. 58, 2005 pp. 19.

[25] R. Tisserand, M. Rebetez, M. Grivet, S. Bouffard, A. Benyagoub, F. Levesque, J. Carpena, Nucl. Instrum. Methods Phys. Res. Sect. B 215 (2004) 129.

[26] L.M. Wang, M. Cameron, W.J. Weber, K.D. Crowley, R.C. Ewing, Hydroxyapatite and Related Materials, Crc Press Inc, Boca Raton, 1994. p. 243.

[27] M. Toulemonde, W. Assmann, C. Dufour, A. Meftah, F. Studer, C. Trautmann, in: P. Sigmund (Ed.), Ion Beam Science Solved and Unsolved Problems Pts 1 and 2 , vol. 52, Royal Danish Academy Sciences \& Letters, CopenhagenV, 2006, p. 263. 